\title{
Qualitative Properties and Antibacterial Activity of Essential Oil obtained from Citrus sinensis Peel on Three Selected Bacteria
}

\author{
Nwachukwu $\mathrm{BC}^{1 *}$, Taiwo $\mathrm{MO}^{2}$, Olisemeke $\mathrm{JK}^{3}$, Obero $\mathrm{OJ}^{1}$ and Abibu $\mathrm{WA}^{4}$ \\ ${ }^{1}$ Department of Science Laboratory Technology, Federal College of Animal Health and Production Technology, Moor \\ Plantation, Nigeria
}

${ }^{2}$ Department of Microbiology, Chrisland University, Abeokuta, Nigeria

${ }^{3}$ Department of Industrial Chemistry, Imo State University, Nigeria

${ }^{4}$ Department of Microbiology, Federal University of Agriculture, Nigeria

*Corresponding author: Nwachukwu BC, Department of Science Laboratory Technology, Federal College of Animal Health and Production Technology, Moor Plantation, Ibadan, Nigeria

\section{ARTICLE INFO}

Received: 幽 July 03, 2019

Published: 幽 July 11, 2019

Citation: Nwachukwu BC, Taiwo MO, Olisemeke JK, Obero OJ, Abibu WA. Qualitative Properties and Antibacterial Activity of Essential Oil obtained from Citrus sinensis Peel on Three Selected Bacteria. Biomed J Sci \& Tech Res 19(4)2019. BJSTR. MS.ID.003323.

\begin{abstract}
Medicinal plants are essential curative agents for different types of ailments. Citrus sinensis contains important micronutrients such as vitamin $\mathrm{C}$ and $\mathrm{E}$, carotenoids and flavonoids, essential for maintenance of human health. The antibacterial activities of its essential oil were assessed against three selected bacteria. The result showed that the essential oil extracted with hot ethanol at $100 \mu \mathrm{L}$ had a better inhibitory ability of 16 $\mathrm{mm}, 15 \mathrm{~mm}$ and $16 \mathrm{~mm}$ against Bacillus sp., Escherichia coli and Staphylococcus aureus respectively as compared to aqueous (cold and hot) $11 \mathrm{~mm}, 10 \mathrm{~mm}, 13 \mathrm{~mm}$ and cold ethanol (13 mm, $13 \mathrm{~mm}$ and $14 \mathrm{~mm}$ ). The GC/MS analyses revealed that the orange peel oil extract is mainly composed of terpene hydrocarbons, oxygenated compounds and nonvolatile compound, many which constitute the antibacterial properties of the extract. It can be concluded that hot ethanol can be used for the extraction of oil from orange peel in the production of drugs for used in the treatment of Escherichia coli and Staphylococcus aureus.
\end{abstract}

Keywords: Phytochemical; Essential Oil; Antimicrobial; Antibiotics

\section{Introduction}

The spread of drug resistant microbial pathogens is one of the most serious threats to successful treatment of infectious diseases [1]. Some researchers reported that there is a relationship between chemical structures of the most abundant essential oil and antibacterial activity [2,3]. Plant derived components are a major area of interest to source for safer and more effective antibacterial agents [1]. Medicinal plants are essential curative agents for different types of ailments. To know the degree of effectiveness and enhance the use of herbal medicine, it is necessary to ensure intensive study of plants that are of medicinal importance. The Citrus sinensis contains important micronutrients namely vitamin $\mathrm{C}$ and E, carotenoids and flavonoids, essential for maintenance of human health. Multiple dietary sources of these compounds are present virtually in all plant material [4]. The nutritional importance of foods is due to the presence of these functional food ingredients and antioxidant nutraceuticals. The essential oil obtained from Citrus sinensis are found to have many medicinal properties and is widely used against various ailments such anaesthetic, anodyne, antiseptic, astringent, deodorant, diaphoretic, disinfectant, expectorant, febrifuge, fumigant, haemostat, inhalant, insect repellent [5], cold, stomach upset, cancer, diuretic, cormunative, immuno-enhancing, stomachic, tonic to the digestive system, immune system and skin. It is also used to treat and prevent vitamin deficiencies, colds, flu and scurvy and helping to fight viral and bacterial infections [6].

The medical potency of sweet orange (Citrus sinensis) is due to its high content in vitamin $\mathrm{C}$ which is believed to stimulate the 
production of white blood cells, primarily neutrophils, which attack foreign antigens such as bacteria and viruses [7]. It also boosts the body's production of antibodies and interferon which help protect the body from viral invaders and cancer cells $[8,9]$. The aim of this study is to determine the qualitative properties and antibacterial activity of essential oil obtained from Citrus sinensis peel on three selected bacteria (Bacillus sp., Escherichia coli and Staphylococcus aureus).

\section{Materials and Methods \\ Experimental Site}

The sweet orange samples were bought from Oje market Ibadan, Oyo state. The antimicrobial analysis was carried out at the National Institute of Science Laboratory Technology (N.I.S.L.T) Samonda, Ibadan, Oyo state. The qualitative analysis was carried out at the Chemistry Laboratory of Federal College of Animal Health and Production Technology, Moor Plantation, Ibadan.

\section{Sample Collection and Preparation}

A total of 100 oranges were purchased, washed with running tap water followed by sterile distilled water. The sweet oranges were peeled with knives; the peels were air dried at room temperature for two days and were pulverized into fine powder by grinding using a sterile mixer grinder and stored in air tight bottles before taken to the Chemistry laboratory for extraction.

\section{Extraction process of the Essential Oil}

The pulverized dried orange peels were divided into four parts for extraction using different solvents (hot and cold aqueous and ethanol). Two different solvents were used for the extraction; Ethanol (hot and cold ethanol) and water (hot and cold water) according to the method of Hussain et al. [10] with little modification

\section{Extraction of Oil Pulverized Sweet Orange Peel using Hot Ethanol and Aqueous (Water)}

For the extraction of essential oil using hot ethanol and aqueous, $10 \mathrm{~g}$ of the pulverized orange peel were measured separately for the ethanol and aqueous extraction process. Ethanol and aqueous (water) of $250 \mathrm{~cm} 3$ were also measured separately using a measuring cylinder and were poured into the Soxhlet apparatus. Ethanol was allowed to boil at $78^{\circ} \mathrm{C}$ while aqueous was boiled at $100^{\circ} \mathrm{C}$. The essential oil was then extracted into a thimble.

\section{Extraction of Oil from Pulverized sweet Orange Peel using Ethanol and Aqueous (Water)}

The pulverized orange peels ( $10 \mathrm{~g}$ ) were soaked in water and ethanol ( $250 \mathrm{~mL}$ ) separately for two days and then poured into the water distiller where the extraction of the essential oil was done.

\section{Antibacterial Sensitivity of Essential Oil using different Solvents}

\section{Sub-culturing and confirmation of Bacterial Isolates}

Three bacterial isolates namely Escherichia coli N2B, Bacillus sp. SLR4 and Staphylococcus aureus G5R were collected from the Microbiology Laboratory, National Institute of Science Laboratory Technology (N.I.S.L.T). These bacterial isolates were subcultured in an already prepared nutrient agar medium and confirmed by Gram staining and Biochemical tests [11,12].

\section{Inoculation of Extract}

Steriled Petri dishes were labeled accordingly with different isolates at $50 \mu \mathrm{L}$ and $100 \mu \mathrm{L}$ extract (Essential Oil). Each plate that contains cold water, hot water, cold ethanol and hot ethanol were labeled as 1, 2, 3, and 4 respectively. Agar well diffusion method was used by making holes on the sterilized nutrient agar using cork borer. The extracts (Essential oil) at $50 \mu \mathrm{L}$ and $100 \mu \mathrm{L}$ was then introduced into the holes and incubated for 24 hours at $37^{\circ} \mathrm{C}$.

\section{Comparison between the resistance of standard Antibiotics and Essential oil on the selected bacterial isolates}

The resistance of standard antibiotics namely Ceftazidime (CAZ), Cefuroxime (CRX), Gentamicin (GEN), Cefixime (CXM), Ofloxacin (OFL), Augmentin (AUG), Nitrofurantion (NIT) and Ciprofloxacin (CPR) were compared with the Essential oil extract by streaking the test organisms (Escherichia coli N2B, Bacillus sp. SLR4 and Staphylococcus aureus G5R) against each of them. They were then incubated for 24 hours at $37^{\circ} \mathrm{C}$ and the zones of inhibitions were measured to the resistance of the antibiotics and the extracts.

\section{Phytochemical Analysis}

The qualitative analysis of the essential oil (hot and cold ethanol extract, hot and cold water extracts) was assessed to confirm the phyto-chemical properties. The following phyto-chemical analyses were assayed for:

Flavonoids Test: Two $\mathrm{mL}$ of essential oil was added to few drops of sodium hydroxide. The change in the colour solution from intense yellow color to colorless on addition of dilute acid proves the presence of flavonoids.

Phenol Test: Two $\mathrm{mL}$ of essential oil extract was added to $2 \mathrm{~mL}$ of $5 \%$ ferric chloride solution $\left(\mathrm{FeCl}_{3}\right)$, the formation of a deep bluish green solution confirms the presence of phenols.

Terpenoids Test: Five $\mathrm{mL}$ of essential oil extract was mixed with $2 \mathrm{~mL}$ of Cloroform followed by $3 \mathrm{~mL}$ of concentrated $\mathrm{H}_{2} \mathrm{SO}_{4}$. Then, $1 \mathrm{~mL}$ of extract of each solvent was added to $0.5 \mathrm{ml}$ of chloroform followed by a few drops of concentrated sulphuric acid, 
formation of reddish brown precipitate indicates the presence of terpenoids in the extract.

Cardiac Glycosides Test: Two $\mathrm{mL}$ of glacial acetic acid was added to a drop of $2.0 \% \mathrm{FeCl}_{3}$. The solution was then mixture with $10 \mathrm{ml}$ of essential oil extract and $1 \mathrm{ml}$ of concentrated sulfuric acid $\left(\mathrm{H}_{2} \mathrm{SO}_{4}\right)$. A brown ring formed between the layers indicates the entity of cardiac steroidal glycosides.

Saponins: Two $\mathrm{ml}$ of the filtered extract sample was mixed with $1 \mathrm{ml}$ of distilled water in a test tube and it was rocked vigorously to obtain a stable persistent forth. The frothing was mixed with 3 drops of olive oil and mixed vigorously. The foam appearance indicates the presence of saponins.

Alkaloids Test: Two grams of extract was added to $10 \mathrm{~mL}$ solution of methanol and $1 \% \mathrm{HCl}$ on water bath and then filtered. Two mL. One $\mathrm{mL}$ of the filtrate was added to 6 drops of Dragendroff reagent. A precipitated orange colour infers the presence of alkaloid.

\section{Gas Chromatography/ Mass Spectrometry (GC/MS) Analysis}

The extraction of the active ingredient was carried out by dissolving $10 \mathrm{~mL}$ of the essential oil in $20 \mathrm{~mL}$ of $99.99 \%$ pure n-hexane in a well corked reagent bottle. This was thoroughly mixed using an Ultra sonicator for a period of five hours. The mixture was allowed to stand for 72 hours and filtered into a beaker; the mixture was rewashed with $20 \mathrm{~mL}$ n-hexane for two more consecutive times. The combined aliquots were evaporated on a steam berth to $5 \mathrm{~mL}$ and filtered through pasture pipette stocked with glass wool (membrane) with packed anhydrous sodium sulfate to remove the left over moisture. The filtrate was concentrated to $1 \mathrm{~mL}$ in the vial bottle and was taken to analyze on Gas chromatography for the chemical composition.

The Gas chromatographic model used was 7890A, GC analysis was performed on an agilent technologies interfaced with Mass selective detector model 5975C (MSD). The electron ionization was at 70 volts with ion source temperature of $250^{\circ} \mathrm{C}$. Highly pure helium gas (99.9\% purity) was used as carrier gas while HP-5ms $(30 \mathrm{~mm} \times 0.25 \mathrm{~mm} \times 0.32 \mu \mathrm{m})$ was used as the stationary phase. The oven temperature was at $80^{\circ} \mathrm{C}$ held for 4 minutes and ramped to $270^{\circ} \mathrm{C}$ at the rate of $3.5^{\circ} \mathrm{C} /$ minutes holing for 6 minutes. $1 \mu / \mathrm{l}$ was auto injected.

Table 2: Zones of Inhibition (mm) of essential oils on the test isolates.

\begin{tabular}{|c|c|c|c|c|c|}
\hline \multirow{2}{*}{ Isolates } & Hot aqueous & Cold aqueous & Cold Ethanol & Hot Ethanol & Hot Ethanol \\
\cline { 2 - 6 } & $\mathbf{1 0 0} \boldsymbol{\mu} \mathbf{L}$ & $\mathbf{5 0} \boldsymbol{\mu L}$ & $\mathbf{1 0 0} \boldsymbol{\mu L}$ & $\mathbf{5 0} \boldsymbol{\mu L}$ & 11 \\
\hline Bacillus sp. & 12 & 11 & 13 & $13 \mathbf{L}$ & 16 \\
\hline E. coli & - & 10 & 14 & 16 & 15 \\
\hline S. aureus & - & 13 & 16 & 16 \\
\hline
\end{tabular}

\section{Sensitivity test using common Antibiotics disc on Test Organisms}

Table 3 showed the result of effects of commonly used antibiotics disc against Bacillus sp., Escherichia coli and Staphylococcus aureus.

\section{Results}

\section{Qualitative Analysis of the Phyto-chemical components in the Essential Oil obtained from Citrus sinensis Peels}

Table 1 showed the phyto-chemical components of the essential oil extracted from Citrus sinensis peels using different solvents such as aqueous (cold and hot) and ethanol (hot and cold). The results indicated that all the phyto-chemicals assayed for were all present in the extract except in the cold aqueous and hot aqueous which showed the absence of flavonoids.

Table 1: Qualitative analysis of the phyto-chemical components in the essential oil obtained from citrus sinensis peels.

\begin{tabular}{|c|c|c|c|c|}
\hline \multirow{2}{*}{ Phyto-chemicals } & \multicolumn{4}{|c|}{ Inference of Extracts } \\
\cline { 2 - 5 } & $\mathbf{1}$ & $\mathbf{2}$ & $\mathbf{3}$ & $\mathbf{4}$ \\
\hline Flavonoids & - & - & + & + \\
\hline Phenols & + & + & + & + \\
\hline Terpenoids & + & + & + & + \\
\hline Cardiac glycoides & + & + & + & + \\
\hline Saponins & + & + & + & + \\
\hline Alkaloids & + & + & + & + \\
\hline
\end{tabular}

Keys: Extract 1: Cold aqueous; Extract 2: Hot aqueous; Extract 3: Cold Ethanol; Extract 4: Hot water. +Present, - Absent

\section{Zones of Inhibition (mm) of Essential Oils on the test Isolates}

Table 2 showed the zones of inhibition ( $\mathrm{mm}$ ) using the essential oil obtained from Citrus sinensis peel on Bacillus sp., Escherichia coli and Staphylococcus aureus at different concentrations of 50 and 100 $\mu \mathrm{L}$ using different solvents (aqueous and ethanol; cold and hot). From the result obtained, the antibiotics sensitivity test carried out using Essential oil extracted with cold aqueous of 50 and $100 \mu \mathrm{L}$ showed a clear zone of inhibition on all the test isolates. In contrary, Essential oil extracted with hot aqueous $100 \mu \mathrm{L}$ only had a clear zone of inhibition of $12 \mathrm{~mm}$ on Bacillus sp. but could not inhibit Escherichia coli and Staphylococcus aureus. Essential oil obtained with other solvents has varying degrees of inhibition against the test organisms. However, it was observed that the essential oil extracted with hot ethanol $(100 \mu \mathrm{L})$ had a better inhibitory ability compared to aqueous (cold and hot) and cold ethanol. 
while Ofloxacin had the same measurement of $25 \mathrm{~mm}$ against the test isolates. Essential oil extracted using hot ethanol had the best inhibitory effects against the test isolated compared to essential oil obtained from aqueous (hot and cold) and cold ethanol.

Table 3: Zones of Inhibition ( $\mathrm{mm}$ ) of essential oils on the test isolates.

\begin{tabular}{|c|c|c|c|}
\hline \multirow{2}{*}{$\begin{array}{c}\text { Antibiotics used and } \\
\text { Concentration }(\boldsymbol{\mu g})\end{array}$} & \multicolumn{3}{|c|}{ Measured zone of inhibition (mm) } \\
\cline { 2 - 4 } & $\boldsymbol{E}$. coli & S. aureus & Bacillus $\boldsymbol{s}$. \\
\hline Gentamicin (10) & 16 & 12 & 16 \\
\hline Cefixime (30) & - & - & - \\
\hline Ofloxacin (5) & 25 & 25 & 25 \\
\hline Augmentin (30) & - & - & - \\
\hline Nitrofurantion (300) & - & - & - \\
\hline Ceftazidime (30) & - & - & - \\
\hline Cefuroxime (30) & - & - & - \\
\hline
\end{tabular}

Keys: Negative (No growth), E. coli - Escherichia coli, S. aureus -

Staphylococcus aureus, mm-millimeter, $\mu \mathrm{g}$-microgram.

\section{Compounds detected from Essential Oils using Gas Chromatography/ Mass Spectrometry}

Gas Chromatography was carried out to ascertain the active compounds in the essential oil. Table 4 showed the result of compounds detected, number of carbon, value of compound (\%) and the retention time (minutes) from the essential oil extracted using hot ethanol. The compounds detected were Tetradecane, Decahydro-1,1,4a,5,6-pentamthylna Pentadecane, Hexadecane,
Heptadecane, Octadecane, Nonadecane, n-Hexadecanoic acid (Palmitic acid), Heneicosane, Tricosane and Tetracosane.

Table 4: Compounds detected from essential oils using gas chromatography/ mass spectrometry.

\begin{tabular}{|c|c|c|c|c|}
\hline Sample ID & $\begin{array}{l}\text { Name of } \\
\text { Compound }\end{array}$ & $\begin{array}{c}\text { No of } \\
\text { Carbon }\end{array}$ & $\begin{array}{c}\text { Value of } \\
\text { Compound } \\
\text { (\%) }\end{array}$ & $\begin{array}{c}\text { Retention } \\
\text { Time } \\
\text { (Mins) }\end{array}$ \\
\hline \multirow{11}{*}{$\begin{array}{l}\text { Ethanol } \\
\text { Extraction }\end{array}$} & Tetradecane & C14 & 1.845 & 9.488 \\
\hline & $\begin{array}{c}\text { Decahydro- } \\
\text { 1,1,4a,5,6- } \\
\text { pentamethylna }\end{array}$ & C15 & 1.551 & 9.74 \\
\hline & Pentadecane & C15 & 4.299 & 10.793 \\
\hline & Hexadecane & C16 & 5.17 & 12.033 \\
\hline & Heptadecane & $\mathrm{C} 17$ & 6.254 & 13.214 \\
\hline & Octadecane & C18 & 7.052 & 14.331 \\
\hline & Nonadecane & C19 & 6.104 & 15.522 \\
\hline & $\begin{array}{c}\text { n-Hexadecanoic } \\
\text { acid (Palmitic } \\
\text { acid) }\end{array}$ & C16.0 & 4.154 & 16.549 \\
\hline & Heneicosane & $\mathrm{C} 21$ & 5.752 & 18.188 \\
\hline & Tricosane & $\mathrm{C} 23$ & 4.418 & 21.118 \\
\hline & Tetracosane & $\mathrm{C} 24$ & 4.2 & 22.621 \\
\hline
\end{tabular}

\section{Chromatogram peaks of compounds from Essential Oil} from of Citrus Sinensis Peel

The scanned representation of GC/MS results with peaks showed the compounds detected from the essential oils (Figure 1).

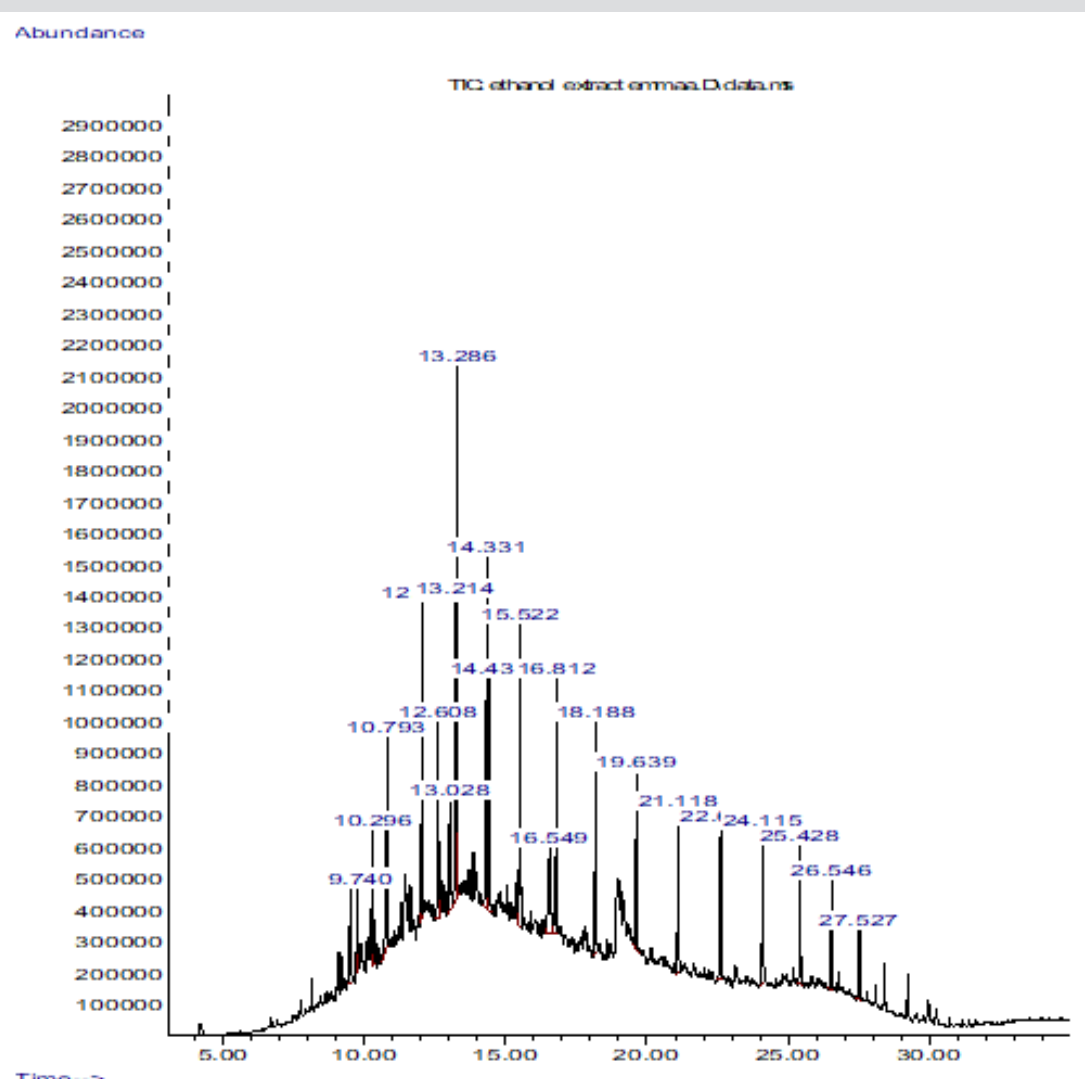

Figure 1: Chromatogram peaks of compounds from essential oil of citrus sinensis peel. 


\section{Discussion}

The qualitative and quantitative analysis from this study revealed the presence of phyto-chemical properties in the analysed essential oil form samples 1 (cold aqueous), 2 (hot aqueous), 3 (cold ethanol) and 4 (hot ethanol). The Essential oil extracted using water or aqueous (cold and hot) did not show the presence of flavonoids. The absence of flavonoids in these essential oil samples from Citrus sinensis peel is contrary to what was reported by Sun [13]. Flavonoids, among others are known to be produced by plants in response to microbial infection [14]. In this present study saponin was present in all essential oil samples; this is in accordance to the work of Kumar et al. [15] who reported that essential oil obtained from Citrus sinensis peel using ethanol had high quantity of saponin.

From the result obtained from this study, essential oil extracted using aqueous (hot and cold) did not show any inhibitory properties against $E$. coli and S. aureus while essential oil from hot aqueous showed a clear zone of inhibition against Bacillus sp. The result from this study is similar to what was reported by Abalaka and Bello [6]. Essential oil obtained from ethanol (hot and cold) had higher inhibitory properties, this result also support the findings of Cowen [16] who reported that the potency of Citrus fruit peel is enhanced by the ethanol used; which indicates that there are some active ingredients in orange peel which have high antimicrobial effect. The antibiotics compounds already identified in plants are reportedly aromatic or saturated organic molecules which can easily solubilised in organic solvents.

The phyto-chemicals in this study have inhibitory properties and are secondary metabolites produced by plants that fight with microorganisms in their environment. The inhibitory properties of the essential oil (hot and cold) which contain flavonoids may be due to their ability to compete with extracellular and soluble proteins of bacterial cell walls, as also reported by Dhiman et al. [9]. The essential oil obtained using ethanol had the ability to inhibit the growth of the most of the test isolates. This is similar to a research carried out by Hashem et al. [17]. The activities of the compounds have been used widely to fight against cells of foreign organisms and potential use in the elimination and reduction of pathogenic diseases (human cancer) $[16,18]$. The presence of saponins also aid in the inhibiting the growth of the test organisms [18]. The inhibitory effect of saponins has effect on inflamed cells and is found to be present in the extracts of Citrus sinensis peel [19]. In this present study, the presence of terpenoids in ethanolic extracts is speculated to be involved in membrane disruption by the lipophilic compounds [20].

Results obtained from the antibacterial sensitivity test in this study, showed that there were no zones of inhibition on Essential oil extracted using hot and cold water at 50 and $100 \mu \mathrm{l}$ on E. coli and S. aureus; This is similar to what was reported by Dhiman et al. [9]. Essential oil obtained from Citrus sinensis peel using ethanol had clear zones of inhibition against all test isolates. Therefore, it can be said that the essential oil has an inhibitory property; which is similar to the research carried out by Ahonkha et al. [21]. The antibacterial activity observed in this study may be attributed to the phyto-chemical constituents of the extracts. In this present study, the essential oil obtained using hot ethanol showed better antimicrobial activity compared to essential oil from aqueous and cold ethanol. This is in support to the study conducted by Jeyaseelan and Jashothan [2]. The better activity of hot extracts may be due to the chemical changes caused by the hot treatment, and the resulting bio-molecules may be more active than the bio-molecules found in the cold extracts. This study also recorded an increase in zones of inhibition at higher concentration which is similar to the report of Judaki et al. [22]. The phyto-chemical compounds are known to be biologically active at higher concentrations and therefore aid the antimicrobial activities of the plants.

In the antibiotics sensitivity disc pattern, it was observed that Gentamicin $(10 \mu \mathrm{g})$ and Ofloxacin $(5 \mu \mathrm{g})$ had zones of inhibition on the test isolates. This is in accordance with the research work of Shimada [23]. Gentamicin has the ability to treat several types of bacterial infections like meningitis and Ofloxacin has the inhibitory properties to inhibit the growth of Bacillus sp., Escherichia coli and Staphylococcus aureus, which are useful for the treatment of bacterial infections like bone and joint infections, urinary tract infections. The results also revealed the potency of the orange peel extracts on the organisms. Generally, against the bacteria isolates, higher concentration of the extract shows a greater zone of inhibition; this is in agreement with the report of Bisno and Stevens [24]. However, Abalaka and Bello [6] stated that the higher the concentration of antibacterial substance, the higher it shows an appreciable zone of inhibition. Israa and Ibrahim [25] in their studies on the antibacterial activities of plant extracts on $S$. aureus and E. coli also reported that the extracts had profound activities on the test organisms.

In the present work, GC/SM chromatogram of the orange peel oil extracts displayed peaks indicating compounds. The compounds detected are similar to the findings of Zahra et al. [26] and Cholke et al. [27]. The GC/MS analyses discovered that the orange peel oil extract is mainly composed of terpene hydrocarbons, oxygenated compounds and non-volatile compounds. Some of these compounds identified constitute the antibacterial properties of the oils. These compounds are environmental friendly and relatively safe solvent which makes them active ingredients of choice in many applications such as medical uses (antibacterial and antifungal) [28], adhesives, stain removers, cleaners of various strippers [29] and agricultural uses such as insect repellents [30,31].

\section{Conclusion}

Based on the result obtained, the use of ethanol (hot and cold) at 50 and $100 \mu \mathrm{l}$ had antibacterial inhibitory ability against Escherichia coli and Staphylococcus aureus while extraction using water did not inhibit the growth of the test isolates. This suggests that ethanol is better solvent for the extraction. 


\section{References}

1. Mann A, Yahaya Y, Banso A, Ajayi GO (2008) Phytochemical and antibacterial screening of Anogeissus leiocarpus against some microorganisms associated with infectious wounds. African Journals of Microbiology Research 2: 060-062.

2. Jeyaseelan EC, Jashothan PT (2012) In vitro control of Staphylococcus aureus (NCTC 6571) and Escherichia coli (ATCC 25922) by Ricinuscommunis L. Asian Pac J Trop Biomed 2: 717-721.

3. Kluytmans J, van Belkum A, Verbrugh H (2007) Nasal carriage of Staphylococcus aureus: epidermiology, underlyimg mechanisms and associated risks. Clin Microbiol Rev 10(3): 505-520.

4. Di Majo, Giammanco D, Guardia, M, Tripoli M, Giammanco E, et al. (2007) Flavanones in Citrus fruit: Structure antioxidant activity relationships. Food Res Int 38: 1161-1166.

5. Shetty B (2016) Assessment of antioxidant, antibacterial and phytochemical analysis peel of Citrus sinensis. Pak J Pharmeutical science 28: 231-239.

6. Abalaka ME, Bello AO (2016) Antibacterial activity of Citrus sinensis (Orange) peel on bacterial isolates from wound. Journal of Microbiology Research 1: 161-168.

7. Nicolosi E, Deng ZN, Gentile A, La Malfa S, Continella G, et al. (2000) Citrus phylogeny and genetic origin of important species as investigated by molecular markers. Theoretical and Applied Genetics 100: 11551166.

8. Uddoh CK (1998) Nutrition. Macmillan Publishers Ltd., London, UK, p. 71-97.

9. Dhiman A, Nanda A, Ahmed S, Narasimham B (2012) In vitro antimicrobial status of methanolic extracts of Citrus sinensis fruit peel. Chronicles of Young Scientists 3(3): 204-208.

10. Hussain AI, Anwar F, Sherazi ST H, Przbylski R (2018) Chemica composition, antioxidant and antimicrobial activities of basil (Ocimum basilicum) essential oils depends on seasonal variations. Food Chem 108: 986-989.

11. Fawole MO, Oso BA (1998) Laboratory manual of Microbiology. Spectrum Book, Ibadan, Nigeria. p. 1-55.

12. Cheesbrough M (2006) District laboratory practice in tropical countries, Part 2. Cambridge University Press, UK, pp. 143-157.

13. Sun J (2007) D-limonene: Safety and clinical applications. Altern Med Rev 12(3): 259-264.

14. Hodek P, Trefil P, Stiborová M (2007) Flavonoids-potent and versatile biologically active compounds interacting with cytochrome P450. Chemico-Biology International 139: 1-21.

15. Kumar K, Narayani M, Subanthini A, Jayakumar M (2011) Antimicrobial activity andphyto-chemical analysis of citrus fruit peels-utilization of fruit waste. Int Engin Sci Technolo 3(6): 5414-5421.

\section{ISSN: 2574-1241}

\section{DOI: 10.26717/BJSTR.2019.19.003323}

Nwachukwu BC. Biomed J Sci \& Tech Res

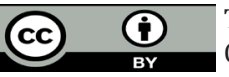

This work is licensed under Creative

Commons Attribution 4.0 License

Submission Link: https://biomedres.us/submit-manuscript.php
16. Cowen MM (2009) Plant products as antimicrobial agents. Clin Microbiol Rev 12: 564-582.

17. Hashemi J, Platz A, Ueno T, Stierner U, Ringborg U, et al. (2009) CDKN a germ-line mutation in individuals with multiple cutaneous melanomas. Cancer Research. 60: 6864-6847.

18. Sham S, Mohammed H, Priscilla DH, Thirumurugan K (2010) Antimicrobial activity and phytochemical analysis of selected Indian folk medicinal plants. Journal of Pharmaceutical Science Research 1(10): 430-434.

19. Just MJ, Recio MC, Giner RM, Cuéllar MJ, Máñez S, et al. (2008) Antiinflammatory activity of unusual lupane saponins from Bupleurum fruticescens. Planta Med 64: 404-407.

20. Almas K, Skaug N, Ahmad I (2007) An in vitro antimicrobial comparison of miswak extract with commercially available non-alcohol mouthrinses. Int J Dent Hyg 3: 18-24.

21. Ahonkai I, Edogun O, Mu U (2009) Antimicrobial activities of the volatile oils of Ocim bacilicum $L$. and Ocimum gratissimum $L$. against some aerobic dental isolates. Pak J Pharm Sci 22: 405-409.

22. Judaki A, Panahi J, Havasian MR, Tajbakhsh P, Roozegar MA (2014) Study of the inhibitory effect of Quercus coccifera's aqueous extract on Staphylococcus aureus and Pseudomonas aeruginosa In vitro. Bioinformation 10: 689-692.

23. Shimada T (2006) Salivary proteins as a defense against dietary. J Chem Ecol 32: 1149-1163.

24. Bisno AL, Stevens DL (1996) Streptococcal infections of skin and soft tissues. N Engl J Med 334: 240-245.

25. Israa AJ Ibrahim (2015) The activity of medical plant extracts with $\mathrm{Al}_{2} \mathrm{O}_{3}$ nanoparticles on the vitality of bacteria and their genomes. Journal of Chemical and Pharmaceutical Research 7(9): 645-652.

26. Zahra Alhani, Hamid Reza Monsef-Esfahani, Yaghoob Amanzade, Homa Hajimehdipour, Mohammad Ali Faramarzi (2004) GC/MS Analysis of Citrus aurantium $L$. hydrolate and its comparison with the commercial samples. Iranian Journal of Pharmaceutical Research 3: 177-179.

27. Cholke PB, Bhor AK, Shete AM, Sonawane RK (2017) Extraction and GCMS analysis of orange (Citrus sinensis) peel oil. RJLBPCS 2(5): 41-51.

28. Odebiyi A, Sofowora AE (1978) Phytochemical screening of Nigeria medicinal plants II. Lloydia 41: 234-246.

29. Chede PS (2013) Phytochemical analysis of Citrus sinensis pulp. Int J Pharmacognosy Phytochemical Res 4(4): 221-223.

30. Akhilesh K, Raghvendra P, Singh V, Gupta M (2012) Antimicrobial properties of peels of citrus fruits. International Journal of Universal Pharmacy Life Sciences 2(2): 2249-6793.

31. Ehler SA (2011) Citrus and its benefits. J Botany 5: 201-207.

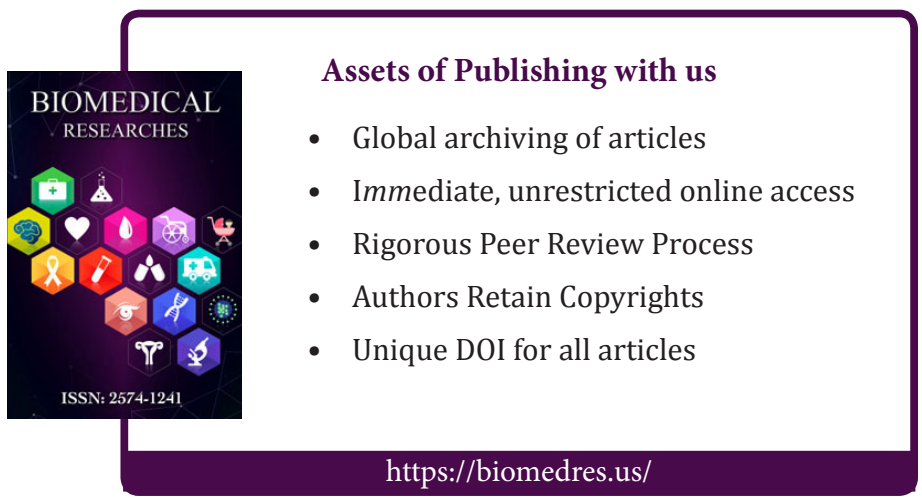

